\title{
An observation into functional aspects of neutrophils in patients with malignant solid tumors before treatment and after chemotherapy and G CSF administration
}

\author{
Parameshwari K ${ }^{1}$, Madhusudhan $\mathbf{U}^{2, *}$ \\ ${ }^{1}$ Assistant Professor, Dept. of Physiology, East Point College of Medical Sciences \& Research Centre, Bangalore, Karnataka, \\ ${ }^{2}$ Assistant Professor, Dept. of Physiology, DMWIMS Medical College, Naseeranagar, Wayanad, Kerala, India
}

*Corresponding Author:

Email: drmadhusudhanu@gmail.com

Received: $20^{\text {th }}$ June, 2018

Accepted: $2^{\text {nd }}$ July, 2018

\begin{abstract}
Introduction: Uncontrolled growth of a group of cells is called cancer. Most of the drugs and therapies used in the management of cancer are immune suppressive.

Objective: The present study was undertaken to observe the functional aspects of neutrophils in patients with malignant solid tumors before treatment and after chemotherapy and G CSF Administration

Materials and Methods: A total of 30 adult male and female patients who were newly diagnosed with malignant tumors were included as cases. 30 normal age and gender matched individuals were included as cases. Collection of blood was performed as per standard guidelines.

Results: There was a significant $(\mathrm{P}$ value $<0.001)$ improvement in the neutrophils percentage after the administration of G CSF. Conclusion: Our results are in accordance with earlier studies as we have observed positive impact on neutrophil percentage followed by the intervention. We recommend further detailed studies in this area with involvement of more parameters and large population.
\end{abstract}

Keywords: Malignant tumors, Chemotherapy, Neutrophil.

\section{Introduction}

Uncontrolled growth of a group of cells is called cancer. Most of the drugs and therapies used in the management of cancer are immune suppressive. ${ }^{1}$ Neutrophils are class of granulocytes that plays a major role in inflammation and infection. They are produced from stem cells along with other formed elements of blood. They are the cells involved in first line defense mechanism.,3 The neutrophils effectively kills the invaded bacteria by a process called phagocytosis. ${ }^{4}$ The development of neutrophils is influenced by the cytokines. Further, The important cytokines that influence the development of neutrophils includes Granulocyte colony stimulating factor(GCSF) and Granulocyte macrophage colony stimulating factor(GM-CSF). ${ }^{7}$ Cytokines increases proliferation of granulocytes through acting on the progenitor cells. ${ }^{5}$ They stimulate all the developmental process of the leucocytes. ${ }^{6,7}$ Interestinglr, the cytokine G-CSF has selectively positive impact on increasing the number of neutrophils. ${ }^{7}$

Development of the tumors which are solid can mostly occurs in the organ systems like gastro intestinal, respiratory systems. The progress of development of the tumor occurs in multiple stages. However, in each stage of development of a tumor, human body has innate protective mechanisms to inhibit the growth of the tumor. Further dietary substances also have an impact on the carcinogenesis. ${ }^{8}$ If the growth of the tumor exceeds $1-2 \mathrm{~mm}$, it causes the angiogenesis. ${ }^{9}$ Factors contributing the inhibition of the tumor include both innate and adaptive immunity. Neutropenia is commonly observed in the patients with cancer. It may be due to under lying cause of the disease or due to the result of chemo therapy. G CSF regulates the mobilization of the neutrohills during normal and in stress conditions effectively. This is very essential for carrying out the inflammation process. However, there are some controversy on effectiveness of GCSF as some studies reported it as effective and some reported as in effective and few reported that it has side effects. The present study was undertaken to observe the functional aspects of neutrophils in patients with malignant solid tumors before treatment and after chemotherapy and G CSF Administration

\section{Materials and Methods}

Study Setting: The current study was carried out at department of Oncology of Vydehi Institute of Medical Sciences and Research Center Bangalore and Apollo Hospital Bangalore.

Participants: A total of 30 adult patients of both genders who were newly diagnosed with malignant solid tumors slotted to receive for the chemotherapy regime of 21 day cycle were included as cases. 30 normal healthy volunteers age and gender matched with that of the cases were recruited as controls. Informed consent was obtained from all the participants before the study.

Methods: Blood sample collection was performed as per standard guidelines. Nitro blue Tetrazolium test (NBT) was used to determine both phagocytic and 
metabolic function. Chemotaxis [Agarose Chemo taxis Assay Measure the distance travelled by white blood cells in millimeter with respect to the FormylMethionyl-Leucyl-Phenylalanine (fMLP).

Data Analysis: Data was analyzed by using SPSS 20.0 version. Data was presented as mean and standard deviation and percentages. One way ANOVA was used to test the significance of difference between the groups. $\mathrm{P}$ value less than 0.05 was considered as significant.

\section{Results}

The results were presented in table 1 . There was a significant $(\mathrm{P}<0.001)$ increase in the number of neutrophils followed by the administration of G CSF. There was a significant improvement in the functional aspect of candicidal function followed by the intervention.

Table 1: Comparison of NFT variables Pre-post G-CSF in cancer patients with solid tumors

\begin{tabular}{|l|c|c|c|}
\hline NFT variables & Pre G-CSF & Post G-CSF & P value \\
\hline Neutrophil count pre CSF (\%) & $62.37 \pm 4.22$ & $66.48 \pm 5.01$ & $<0.001^{* *}$ \\
\hline NBT Stimulated (\% cells) Pre GCSF & $23.33 \pm 17.08$ & $32.68 \pm 26.11$ & $0.065+$ \\
\hline NBT Unstimulated (\%) Pre G CSF & $17.03 \pm 11.22$ & $21.20 \pm 22.56$ & 0.403 \\
\hline $\begin{array}{l}\text { Candidicidal Assay (\% of dead candida) Pre G } \\
\text { CSF }\end{array}$ & $14.33 \pm 10.63$ & $19.03 \pm 0.72$ & $0.021^{*}$ \\
\hline Chemotaxis in mm pre GSF & $0.024 \pm .01$ & $0.0217 \pm 0.009$ & 0.409 \\
\hline $\begin{array}{l}\text { Phagocytosis Pre G-CSF(mean particle } \\
\text { number) }\end{array}$ & $4.96 \pm 0.76$ & $1.73 \pm 0.44$ & $<0.001^{* *}$ \\
\hline
\end{tabular}

(Data was presented as Mean \pm SD)

\section{Discussion}

Treatment of cancer is costly and is involved with several side effects. Most of the drugs used in the treatment of cancer causes decrease in the functioning of the bone marrow. This effect will decrease the ability of bone marrow to produce the formed elements. Neutrophils are the class of granulocytes, produced from pluri potent stem cells. The development of neutron phils is effected by two factors mainly that is granulocyte colony-stimulating factor (G-CSF) and granulocyte-macrophage colonystimulating factor. The more is the decrease in the neutrophil count, the severe is the neutropenia. As neutrophils play a key role in protecting from bacteria and fungus, decrease in the neutrophil count may increase the infections. Hence, there is need for treatment for the cancer patients to prevent the damage of bone marrow. One of the commonly used therapeutic drug is administration of $\mathrm{G}$ CSF. G CSF is a glycoprotein and stimulates all steps in the production of neutrophils. The mechanism of action of GCSF is through G CSF receptors. These receptors are trans membrane receptors. It improves the capacity of bone marrow and also influences all steps of production of blood cells. Hence, the immune functions of the cancer patient can be improved with the treatment. The agent used for the treatment should stimulate all the stages of production of formed elements. ${ }^{7,9}$ Most common treatment used for post chemotherapy was cytokines administration. Currently, granulocyte colony stimulating factor (G-CSF) was considered as a standard treatment for post chemotherapy patients. ${ }^{14}$ Several animal studies have proved the effect of GCSF in reversing the myelosuppression. ${ }^{15}$ It was reported that using the $G$ CSF after the radio therapy increases survival rates. ${ }^{22}$
Apart from this function, the GCSF also plays a protective role to the organ systems like liver, brain and gastro intestinal tract. ${ }^{16-18}$ It was reported that the $G$ CSF has anti tumor effects and through this effect it can cause neutrophilia (19). In contrast, some of the animal studies have reported that the GCSF stimulates the growth of tumors. ${ }^{20,21}$ Earlier studies reported that the effect of GCSF varies with the dose administration. High doses were reported to be more effective in treatment of tumor. ${ }^{23}$ As the G CSF increases the count of neutrophils, they will release the cytotoxic mediators which can effectively destruct the cancer cells. ${ }^{24,25}$ The other factor effect the effectiveness of the administration of G CSF is percentage of immature neutrophils. It was reported that if the percentage of immature neutrophils is less, the G CSF is more effective and in those with high percentage of immature neutrophils, the GCSF is in affective. ${ }^{26}$ Certain studies reported that there may be complications followed by administration of G CSF as it was observed that there was increase in the collagen induced arthritis in mice receiving $\mathrm{G} \mathrm{CSF}^{27} \mathrm{G}$ CSF modulates the gene expression and regulates the mobilization of neutrophils. Contra indications were reported by administration GCSF within 24 hours of chemotherapy. ${ }^{28}$ The route of administration has not got any affect on the potential activity of GCSF. As there was a equal effect observed when GCSF was administered either sub cutaneous or intravenous routes. However, clinically, sub cutaneous is recommended by most of the physicians. This is still more applicable for out patients. ${ }^{29}$

The present study was undertaken to observe the functional aspects of Neutrophils in Patients with Malignant Solid tumors before treatment and after chemotherapy and G CSF Administration. There was a 
significant $(\mathrm{P}<0.001)$ increase in the number of neutrophils followed by the administration of G CSF. There was a significant improvement in the functional aspect of candicidal function followed by the intervention. Our study results support results of earlier studies which was reported decrease in the chemotaxis activity in cancer patients. ${ }^{10}$ However, there are studies which reported contradictory results also. ${ }^{11,12}$ Some of them reported that the therapy is in effective and some reported there were adverse effects after the intervention. The possible reason for this variation in the results may be due to the transit time of the bone marrow. However, this variation in results highlights the need of detailed studies to understand and implement the therapy.

\section{Conclusion}

There was a significant improvement in the neutrophil percentage followed by the administration of GCSF. Our study further supports use of the G CSF as an adjunctive therapy for post chemo therapy patients to keep the neutrophil count in normal limits and to prevent the risk of infections. We recommend further detailed studies in this area with involvement of more parameters and large population. Further multi centre studies also recommended.

Limitations: The study was conducted at one center; hence the results may not be generalized.

Conflicts of Interest: None declared

\section{Source of Funding: Self}

\section{References}

1. Crawford J, Dale DC, Lyman GH. Chemotherapyinduced neutropenia: risks, consequences, and new directions for its management. Cancer. 2004 Jan $15 ; 100(2): 228-37$

2. Schmidt EP, Lee WL, Zemans RL, Yamashita C, Downey GP. On, around, and through: neutrophilendothelial interactions in innate immunity. Physiology (Bethesda). 2011 Oct;26(5):334-47.

3. Souto JC, Vila L, Bru A. Polymorphonuclear neutrophils and cancer: intense and sustained neutrophilia as a treatment against solid tumors. Med Res Rev. 2011 May;31(3):311-63.

4. Witko-Sarsat V, Rieu P, Descamps-Latscha B, Lesavre P, Halbwachs-Mecarelli L. Neutrophils: molecules, functions and pathophysiological aspects. Lab Invest. 2000 May;80(5):617-53.

5. Lieschke GJ, Burgess AW. Granulocyte colonystimulating factor and granulocyte-macrophage colonystimulating factor (2). N Engl J Med. 1992 Jul 9;327(2):99-106.

6. Rapoport AP, Abboud CN, DiPersio JF. Granulocytemacrophage colony-stimulating factor (GM-CSF) and granulocyte colony-stimulating factor (G-CSF): receptor biology, signal transduction, and neutrophil activation. Blood Rev. 1992 Mar;6(1):43-57.

7. Andrew A Lane NB. Non Malignant Disorders of Leukocytes. Decker Intellectual Properties [serial on the
Internet]. 2011: Available from:

www.acpmedicine.com/.../getChapterByIDHTML.action ?...type.

8. Jakobisiak M, Lasek W, Golab J. Natural mechanisms protecting against cancer. Immunol Lett. 2003 Dec 15;90(2-3):103-22.

9. Schreiber TH, Podack ER. A critical analysis of the tumour immunosurveillance controversy for 3-MCAinduced sarcomas. Br J Cancer. 2009 Aug 4;101(3):3816.

10. Gandossini M, Souhami RL, Babbage J, Addison IE, Johnson AL, Berenbaum MC. Neutrophil function during chemotherapy for Hodgkin's disease. Br J Cancer. 1981 Dec;44(6):863-71.

11. Fossat C, Stoppa AM, Sainty D, Blaise D, Viens P, Bayssas M, et al. In vivo stimulation of neutrophil function by lenograstim (glycosylated rHuG-CSF) in oncohematologic patients: results of a phase I trial. Stem Cells. 1994;12(3):322-8.

12. zygier M DL, Szmitkowski M The Effect of Granulocyte -colony stimulating factor on neutrophil functions in children with neutropenia after chemotherapy in the course of Neoplasma. Advances in Medical Sciences. 2007;52:143-6.

13. Shimono N, Okada K, Takeda D, Eguchi K, Misumi H, Sawae Y, et al. Granulocyte colony-stimulating factor does not enhance phagocytosis or microbicidal activity of human mature polymorphonuclear neutrophils in vitro. Clin Diagn Lab Immunol. 1994 Sep;1(5):556-62.

14. Foley, C., Mackey, M.C. Mathematical model for G-CSF administration after chemotherapy. J Theor. Biol.2009;257, 27-44.

15. Uckun FM, Souza L, Waddick KG, Wick M and Song $\mathrm{CW}$ : In vivo radioprotective effects of recombinant human granulocyte colony-stimulating factor in lethally irradiated mice. Blood. 1990;75:638-645.

16. Hou XW, Jiang Y, Wang LF, Xu HY, Lin HM, He XY, $\mathrm{He}$ JJ and Zhang S: Protective role of granulocyte colonystimulating factor against adriamycin induced cardiac, renal and hepatic toxicities. Toxicol Lett. 2009;187:4044.

17. Kim JS, Yang M, Jang H, Oui H, Kim SH, Shin T, Jang WS, Lee SS and Moon C: Granulocyte-colony stimulating factor ameliorates irradiation-induced suppression of hippocampal neurogenesis in adult mice. Neurosci Lett. 2010;486:43-46.

18. Kudo T, Matsumoto T, Nakamichi I, Yada S, Esaki M, Jo Y, Ohji Y, Yao T and Iida M: Recombinant human granulocyte colony-stimulating factor reduces colonic epithelial cell apoptosis and ameliorates murine dextran sulfate sodium-induced colitis. Scand J Gastroenterol. 2008;43:689-697.

19. Lopez-Lazaro M: Granulocyte colony-stimulating factor (G-CSF): A novel anticancer therapy based on the 'universal dynamics of tumor growth'? Exp Oncol. 2006;28:249-251.

20. Natori T, Sata M, Washida M, Hirata $Y$, Nagai R and Makuuchi M: G-CSF stimulates angiogenesis and promotes tumor growth: Potential contribution of bone marrow-derived endothelial progenitor cells. Biochem Biophys Res Commun. 2002;297:1058-1061.

21. Voloshin T, Gingis-Velitski S, Bril R, Benayoun L, Munster M, Milsom C, Man S, Kerbel RS and Shaked Y: G-CSF supplementation with chemotherapy can promote revascularization and subsequent tumor regrowth: Prevention by a CXCR4 antagonist. Blood. 2011;118:3426-3435. 
22. Kim JS, Ryoo SB, Heo K, Kim JG, Son TG, Moon C and Yang K: Attenuating effects of granulocyte-colony stimulating factor (G-CSF) in radiation induced intestinal injury in mice. Food Chem Toxicol. 2012; 50:3174-3180.

23. Garcia-Barros M, Paris F, Cordon-Cardo C, Lyden D, Rafii S, Haimovitz-Friedman A, Fuks Z and Kolesnick R: Tumor response to radiotherapy regulated by endothelial cell apoptosis. Science. 2003;300:1155-1159.

24. Di Carlo E, Forni G, Lollini P, Colombo MP, Modesti A and Musiani P: The intriguing role of polymorphonuclear neutrophils in antitumor reactions. Blood. 2001;97:339345.

25. Koga Y, Matsuzaki A, Suminoe A, Hattori H and Hara T: Neutrophil-derived TNF-related apoptosis-inducing ligand (TRAIL): A novel mechanism of antitumor effect by neutrophils. Cancer Res. 2004;64:1037-1043.

26. Ishikawa K, Tanaka H, Nakamori Y, Hosotsubo H, Ogura $\mathrm{H}$, Nishino M, Shimazu T, Sugimoto H. Difference in the responses after administration of granulocyte colonystimulating factor in septic patients with relative neutropenia. J Trauma. 2000 May;48(5):81424; discussion 824-5.

27. Campbell IK, Rich MJ, Bischof RJ, Hamilton JA. The colony-stimulating factors and collagen-induced arthritis: exacerbation of disease by MCSF and G-CSF and requirement for endogenous M-CSF. J Leukoc Biol. 2000;68:144-150.
28. Scott SD, Chrischilles EA, Link BK, et al. Days of prophylactic filgrastim use to reduce febrile neutropenia in patients with non-Hodgkin's lymphoma treated with chemotherapy. J Manag Care Pharm. 2003;9:15-21.

29. Petros WP. Pharmacokinetics and administration of colony-stimulating factors. Pharmacotherapy. 1992;12:32S-8S.

How to cite this article: Parameshwari K,
Madhusudhan U. An observation into
functional aspects of neutrophils in patients
with malignant solid tumors before treatment
and after chemotherapy and G CSF
administration. Ind J Clin Anat Physiol.
2018;5(3):340-343.

